\title{
THE USE OF AMYL NITRITE IN DIFFERENTIATING MITRAL AND AORTIC SYSTOLIC MURMURS
}

\author{
BY \\ JOHN BARLOW AND JOHN SHILLINGFORD* \\ From the Department of Medicine, Postgraduate Medical School of London \\ Received August 21, 1957
}

The clinical differentiation of the apical systolic murmurs arising at the mitral and aortic valves may be difficult. This is especially so when the murmur of aortic origin is audible only at the apex or is loudest at this site.

Phonocardiography gives further help in that the murmur of aortic stenosis is diamond shaped and ends before the aortic second sound while that of mitral regurgitation is pansystolic and often includes the second heart sound (Leatham, 1951; Besterman, 1955). Where phonocardiography is not available the distinction has to be made on clinical auscultation alone.

The purpose of this paper is to show that the inhalation of amyl nitrite has a different effect on these two murmurs and is therefore useful in their differentiation.

\section{Clinical Observations}

During the first fifteen to twenty seconds after the inhalation of amyl nitrite, the murmur of mitral regurgitation diminishes in intensity and duration: these changes last for at least twenty seconds and thereafter the murmur returns to its original state. The ejection systolic murmur of aortic origin, however, remains unchanged, or increases slightly, during the first twenty seconds then increases to a maximum intensity twenty-five to forty seconds after the inhalation: the murmur then fades and has usually returned to its original intensity 60 to 70 seconds after inhalation of the drug. Where the apical systolic murmur is due to a combination of aortic and mitral valve disease, the regurgitant component fades during the first fifteen to twenty seconds whereas the ejection component increases twenty-five to forty seconds after inhalation.

This clinical test has been applied in over a hundred patients with suspected mitral or aortic valve disease and has, we think, contributed towards an accurate diagnosis. In order to illustrate the effectiveness of the test, however, we selected a group of patients in whom the clinical diagnosis was firmly established on other grounds and recorded the changes produced by amyl nitrite on phonocardiograms.

\section{PHONOCARDIOGRAPHIC OBSERVATIONS}

Thirty patients were studied; ten had definite clinical signs of mitral regurgitation, ten of aortic stenosis, and ten mixed mitral regurgitation and aortic stenosis. An apical phonocardiogram at medium frequency with a simultaneous electrocardiogram was recorded in each patient before the administration of amyl nitrite and every ten to fifteen seconds afterwards for a least two minutes: the tracings were made in expiration.

The phonocardiographic findings are summarized in Table $I$. Where there was no significant change in the systolic murmur, the result was recorded as negative, but changes in the murmurs were divided into slight, moderate, or marked. In the mitral regurgitation group a positive response was

\footnotetext{
* Member Scientific Staff, Medical Research Council.
} 
TABLE I

Changes in Systolic Murmurs after the Administration of Amyl Nitrite, as shown by Phonocardiography

\begin{tabular}{|c|c|c|c|c|c|c|c|c|c|}
\hline & & & & & & Negative & & Positive & \\
\hline Mitral & gurg & tion & & & No. & $\begin{array}{l}\text { No significant } \\
\text { change in SM }\end{array}$ & $\begin{array}{l}\text { Decreas } \\
\text { of } s y\end{array}$ & $\begin{array}{l}\text { length and } \\
\text { lic murmur }\end{array}$ & $\begin{array}{l}\text { ntensity } \\
\text {.M.) }\end{array}$ \\
\hline & & & & & & & Slight & Moderate & Marked \\
\hline $\begin{array}{l}\text { Sinus rhythm } \\
\text { Auricular fibrillation }\end{array}$ & $\begin{array}{l}. . \\
.\end{array}$ & $\begin{array}{l}. . \\
.\end{array}$ & $\begin{array}{l}. . \\
. .\end{array}$ & .. & $\begin{array}{l}6 \\
4\end{array}$ & $\begin{array}{l}0 \\
0\end{array}$ & $\begin{array}{l}2 \\
2\end{array}$ & $\begin{array}{l}2 \\
2\end{array}$ & $\begin{array}{l}2 \\
0\end{array}$ \\
\hline & Total & .. & .. & .. & 10 & 0 & 4 & 4 & 2 \\
\hline & & & & & & Negative & & Positive & \\
\hline Aort & sten & & & & No. & No significant & Incre & in intensity & $\mathrm{SM}$ \\
\hline & & & & & & change in SM & Slight & Moderate & Marked \\
\hline $\begin{array}{l}\text { Sinus rhythm } \\
\text { Auricular fibrillation }\end{array}$ & $\because$. & $\begin{array}{l}. \\
.\end{array}$ & $\begin{array}{l}. . \\
.\end{array}$ & . & 10 & $\underline{0}$ & $\underline{3}$ & $\frac{6}{-}$ & 1 \\
\hline & otal & .. & .. & .. & 10 & 0 & 3 & 6 & 1 \\
\hline & & & & & & Negative & & Positive & \\
\hline Mitral regurgitat & $\mathrm{n}$ anc & torti & enosis & & No. & $\begin{array}{l}\text { No significant } \\
\text { change in SM }\end{array}$ & Early de & $\begin{array}{l}\text { ase and late } \\
\text { intensity }\end{array}$ & crease in \\
\hline & & & & & & & Slight & Moderate & Marked \\
\hline $\begin{array}{l}\text { Sinus rhythm } \\
\text { Auricular fibrillation }\end{array}$ & $\because$. & $\because$. & $\because$. & $\begin{array}{l}. . \\
\ldots\end{array}$ & $\begin{array}{l}7 \\
3\end{array}$ & $\begin{array}{l}1 \\
2\end{array}$ & $\begin{array}{l}2 \\
1\end{array}$ & $\begin{array}{l}3 \\
0\end{array}$ & $\begin{array}{l}1 \\
0\end{array}$ \\
\hline & Total & .. & .. & .. & 10 & 3 & 3 & 3 & 1 \\
\hline
\end{tabular}

accepted when the phonocardiogram showed a significant decrease in the intensity and length of the murmur (Fig. 1 and 2): in all ten cases this result was achieved to varying extent. Conversely, in the group with aortic valve disease a positive result was recorded when the systolic murmur increased after amyl nitrite (Fig. 3): again all ten cases produced a positive response. In the third group of patients with combined mitral and aortic valve lesions the phonocardiographic interpretation was more difficult. A positive response was accepted if the systolic murmur diminished in intensity and duration during the first twenty seconds but then increased to an intensity greater than that of the control record between 25 and 40 seconds. During the first twenty seconds the shape of the murmur tended to become more of the ejection type, presumably due to fading of the regurgitant component. The subsequent increase in intensity after 25 seconds occurred in early or mid systole as would be expected with an increase of the aortic component (Fig. 4). A positive response occurred in seven out of ten cases in this group.

In addition to the specific changes in the murmurs the amyl nitrite usually caused a tachycardia and invariably produced an increase in the first, and a decrease in the second, heart sound.

\section{Discussion}

On clinical auscultation of forty-eight patients with mitral regurgitation, Kahler (1932) observed that after the administration of amyl nitrite there was a decrease or disappearance of the systolic 


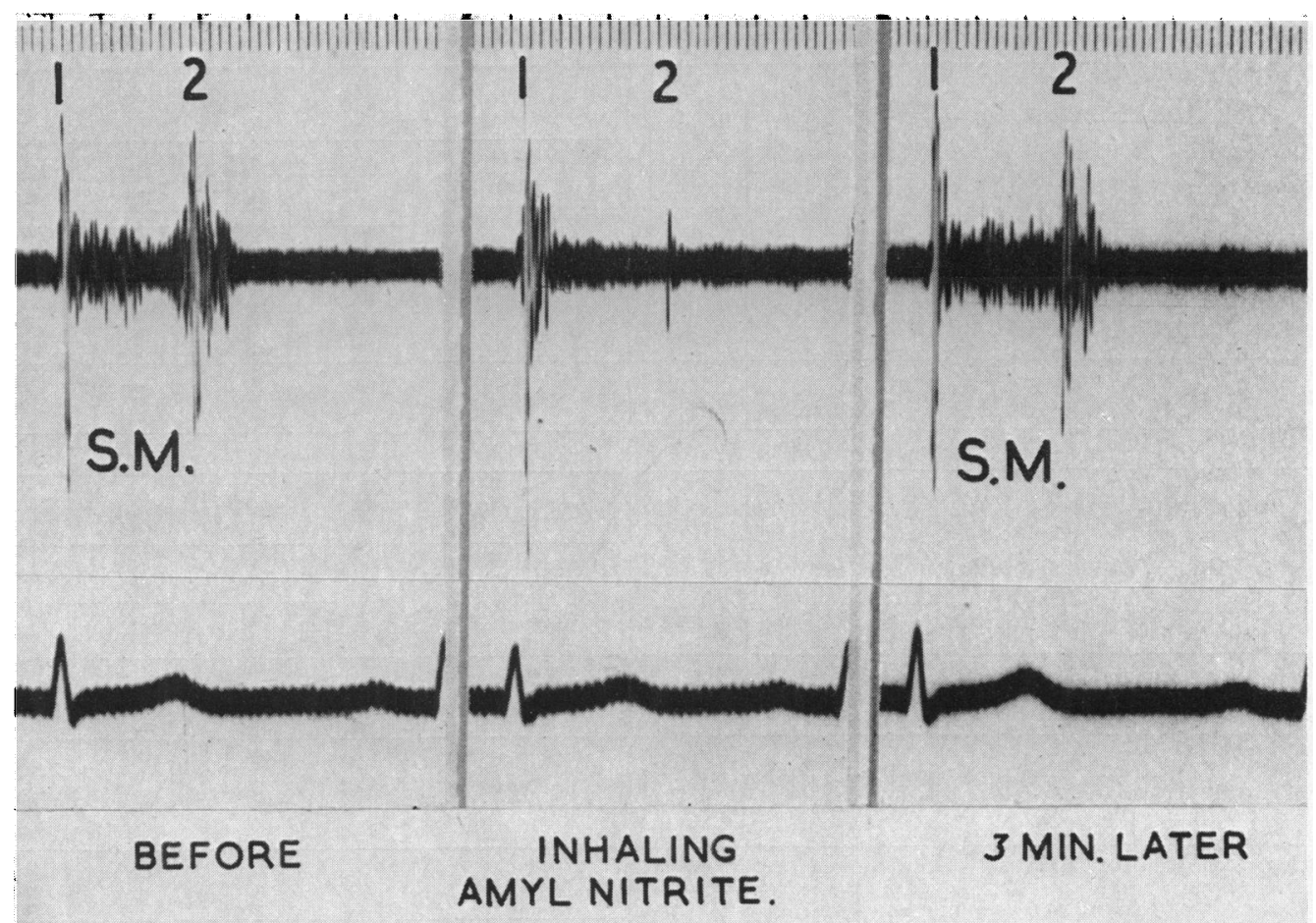

FIG. 1.-The effect of the inhalation of amyl nitrite on the murmur of mitral regurgitation, showing decrease in systolic murmur and second sound with increase in the intensity of the first sound.

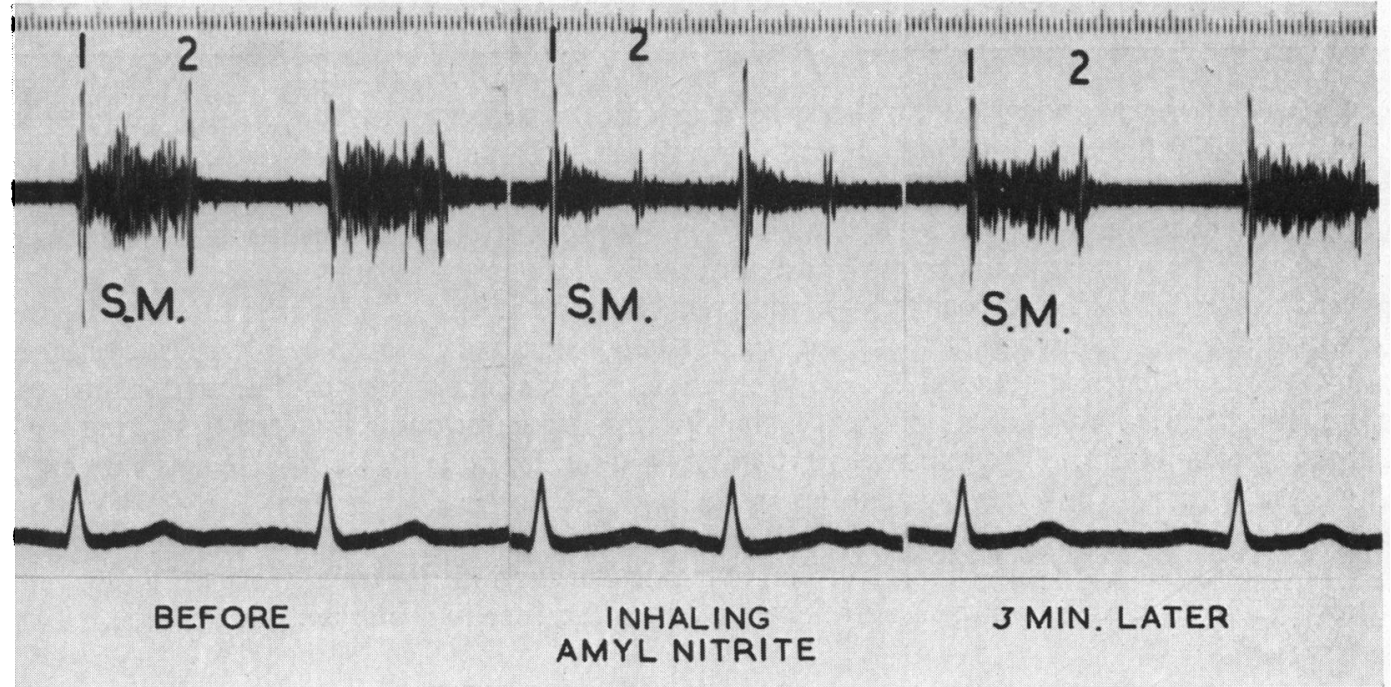

FIG. 2.-The effect of the inhalation of amyl nitrite on the murmur of mitral regurgitation. Note disappearance of murmur in late systole and around the second sound. 


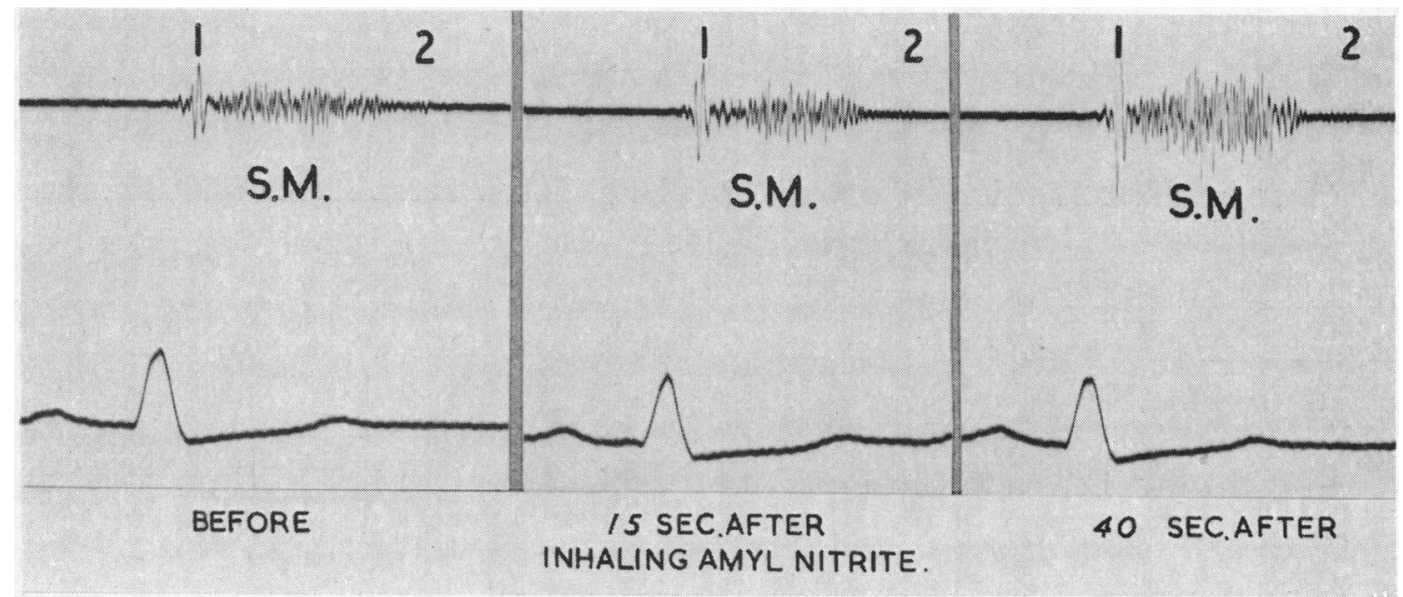

Fig. 3.-The effect of the inhalation of amyl nitrite on the murmur of aortic stenosis, showing progressive increase of systolic murmur up to $\mathbf{4 0}$ seconds.

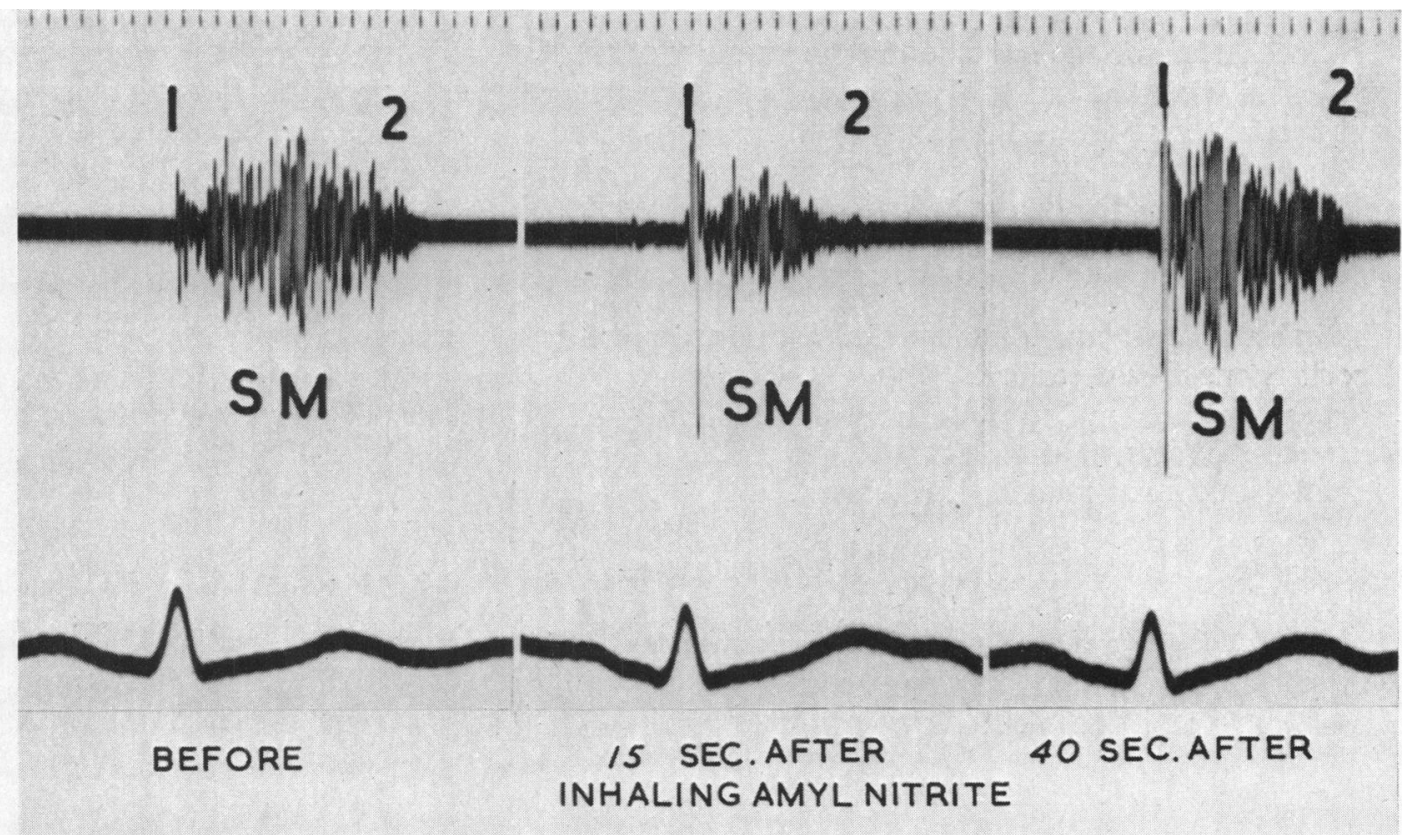

FIG. 4.-The effect of inhaling amyl nitrite on the combined murmurs of aortic stenosis and mitral regurgitation. See text for description of changes. 
murmur in forty-four cases, while in the remaining four the murmur was unchanged. He considered that this feature differentiated the murmur of mitral regurgitation from most functional ("akzidentellen") systolic murmurs which increased with amyl nitrite. Friedlander and Brown (1935) produced transient systolic murmurs with this drug in forty-seven of a hundred patients with normal hearts and Mannheimer (1955), who demonstrated an increase of the "physiologic" systolic murmur in children on phonocardiograms, was of the opinion that the change was due to an increased cardiac output.

While we have found amyl nitrite of use in the clinical differentiation of apical systolic murmurs at the bedside, there are certain conditions under which a correct interpretation of its effect may be difficult. In auricular fibrillation a systolic murmur varies in intensity and duration and this makes the changes produced by amyl nitrite difficult to assess. An overall effect may be apparent on a phonocardiogram when numerous beats are compared, but, unless the change is marked, this is unreliable or impossible on clinical auscultation.

It might appear that the changes shown on the phonocardiogram in a combined aortic and mitral lesion (Fig. 4) would be difficult to appreciate by auscultation. However, whereas a phonocardiogram will only show a change in intensity and duration of the systolic murmur, on clinical auscultation it is also possible to discern alterations in pitch and quality. In addition, we have found that by auscultation outside the apex towards the axilla where the regurgitant component predominates, its fading in the first fifteen to twenty seconds before the increase of the ejection component is more readily appreciated. Auscultation at the apex itself, where the systolic murmur is usually loudest, may be misleading if the ejection component predominates to such an extent that the fading of the regurgitant component is difficult to discern. Where it is suspected that the murmur is arising from both aortic and mitral valves, a more accurate interpretation of the effect of amyl nitrite may be obtained if there are two observers, one listening at or inside the apex, and the other outside the apex towards the axilla. The latter will hear the regurgitant murmur fade within the first twenty seconds whereas the former will hear the ejection component increase between 25 and 40 seconds approximately.

The mechanism of the reduction in the intensity of the systolic murmur in mitral regurgitation by amyl nitrite may be due to the lowering of the peripheral resistance which allows a relatively greater part of the stroke volume to pass forward through the aortic valve. In the absence of other hæmodynamic data, however, this can only be speculative. Similarly the increase in the aortic systolic murmur may be due to an increased stroke output.

\section{SUMMARY}

The effect of the inhalation of amyl nitrite on the apical systolic murmurs of mitral regurgitation and aortic stenosis is described.

It is shown that amyl nitrite decreases the intensity of the murmur of mitral regurgitation but increases that of aortic stenosis.

Its value in clinical practice is discussed.

\section{REFERENCES}

Besterman, E. M. M. (1955). Brit. Heart J., 17, 360.

Friedlander, R. D., and Brown, M. G. (1935). Ann. intern. Meá., 8, 893

Kahler, H. (1932). Wien Arch. inn. Med., 23, 349.

Leatham, A. (1951). Brit. Heart J., 13, 153.

Mannheimer, E. (1955). Advanc. Pediat., 7, 171 